\title{
Effects of Different Operating Temperatures on the Tensile Properties of the Grid Plate Hardfaced with Colmonoy in a Pool Type Sodium Fast Reactor
}

\author{
S. Balaguru, ${ }^{1}$ Vela Murali, ${ }^{2}$ and P. Chellapandi, ${ }^{3,4}$ \\ ${ }^{1}$ Department of Mechanical Engineering, KCG College of Technology, Karapakkam, Chennai, India \\ ${ }^{2}$ Department of Mechanical Engineering, Anna University, Chennai, India \\ ${ }^{3}$ BHAVINI, Kalpakkam, India \\ ${ }^{4}$ SMBS, VIT University, Chennai Campus, Chennai 600 127, India
}

Correspondence should be addressed to S. Balaguru; balaguru_iit@yahoo.co.in

Received 20 November 2016; Accepted 30 January 2017; Published 30 April 2017

Academic Editor: Hyeong-Yeon Lee

Copyright (C) 2017 S. Balaguru et al. This is an open access article distributed under the Creative Commons Attribution License, which permits unrestricted use, distribution, and reproduction in any medium, provided the original work is properly cited.

\begin{abstract}
In sodium-cooled fast reactors (SFRs), the grid plate is a critical component which is made of $316 \mathrm{~L}(\mathrm{~N})$ SS. It is supported on a core support structure which is also made of $316 \mathrm{~L}(\mathrm{~N})$ SS. This assembly is immersed in a pool of sodium which acts as a coolant. If there is a direct contact between the grid plate and the flange of core support structure, self-welding takes place between them at the high operating temperature of SFR by a thin sheet of liquid sodium which gets into the gap between them as this sodium acts as a metallic gum. To avoid self-welding, the bottom plate of the grid plate is hardfaced with Colmonoy 5 by PTAW so that the direct contact between those two components is avoided. Due to the difference in coefficients of thermal expansion between the base metal and the coating, the interface is subjected to tensile force which may weaken the bonding strength between them at higher temperatures. Therefore, the weldment should be able to withstand the tensile force at higher operating temperatures for which hot tensile properties of the base metal and the weldment have been determined to study the compatibility between them after hardfacing for the reliable operation of SFR.
\end{abstract}

\section{Introduction}

Hardfacing alloys should have good mechanical properties for structural applications [1]. They should provide the required wear resistance to base metal without losing their mechanical properties. The mismatch in the coefficient of thermal expansion between the base metal and the coating will affect the mechanical properties of the coating and produce various types of deformation $[2,3]$. Nickel based cobalt-free Colmonoy 5 has been identified as the hardfacing material in nuclear reactors by PTAW. Though the cobalt-base alloys have better galling resistance, these alloys are being replaced by Ni base alloy for lower risk of radiation. The dose rate of Colmonoy 5 is $2.8 \times 10^{5} \mathrm{~Sv} / \mathrm{h}$, whereas the same of Stellite 6 and 12 is $7.5 \times 10^{7} \mathrm{~Sv} / \mathrm{h}$ for the same mass of hardface deposit of $9 \mathrm{~kg}$. Since the dose rate of Colmonoy 5 is low, this is used as the hardfacing alloy by Plasma Transferred
Arc Welding (PTAW) in nuclear reactors [4]. However, the effect of operating temperatures on the tensile behaviour is important. Because the hardfaced alloys lose their ultimate tensile strength and yield strength at higher temperature, the high temperature tensile properties of the alloy should be in line with those of the base metal for better bonding between them without compromising wear-resistant properties of the alloy $[5,6]$.

\section{Need for Hardfacing in the Grid Plate}

In sodium-cooled fast reactors (SFRs), the grid plate is a critical component which is made of $316 \mathrm{~L}(\mathrm{~N})$ SS. It is supported on a core support structure [7]. The grid plate supports the core subassemblies and maintains their verticality. The bottom plate of the grid plate is bolted with the top flange of 




FIGURE 1: Bolted construction of the grid plate with the hardfacing region (http://www.igcar.ernet.in).

the core support structure as shown in Figure 1. The bottom plate of the grid plate is hardfaced in two annular tracks of width of $20 \mathrm{~mm}$ each at diameter of $6360 \mathrm{~mm}$ and at diameter of $6750 \mathrm{~mm}$, respectively. The hardfaced bottom plate of the grid plate is inverted so that the hardfaced annular tracks are in contact with the core support structure flange. If there is no hardfacing, there will be a direct contact between the bottom plate of the grid plate and the flange [8]. Both of these components are made of $316 \mathrm{~L}(\mathrm{~N})$. The entire assembly is immersed in a pool filled with liquid sodium which acts as a coolant. The peak-operating temperature in SFR is $550^{\circ} \mathrm{C}$, which the reactor attains occasionally. However, self-welding starts at $500^{\circ} \mathrm{C}$ between the bottom plate of the grid plate and the flange due to a thin sheet of liquid sodium which gets into the gap between them and fuses them. To avoid selfwelding, hardfacing of the bottom plate of the grid plate has become necessary. Nickel based cobalt-free Colmonoy 5 has been identified as the hardfacing material due to its lower dose rate by PTAW.

\section{Significance of the Study}

The coefficient of thermal expansion of austenitic steel is $1.9 \times$ $10^{-5} / \mathrm{K}$ and that of the Colmonoy is $1.33 \times 10^{-5} / \mathrm{K}$. Therefore, the expansion of steel is faster than that of Colmonoy during heating, and, hence, it is subjected to compressive force induced by Colmonoy. Moreover, Colmonoy, which expands slower than steel, is subjected to tensile force induced by steel [9]. Since the 3 temperatures are important in SFRs, namely, shutdown temperature $\left(200^{\circ} \mathrm{C}\right)$, normal operating temperature $\left(400^{\circ} \mathrm{C}\right)$, and peak temperature $\left(550^{\circ} \mathrm{C}\right)$, the tensile tests were carried out at those temperatures for the parent metal and welded samples separately and the results were compared. The interface is subjected to tensile force during both heating and cooling $\left(200^{\circ} \mathrm{C}\right.$ to $550^{\circ} \mathrm{C}$ and $550^{\circ} \mathrm{C}$ to $200^{\circ} \mathrm{C}$ ). Therefore, the bonding strength of the
TABLE 1: Welding parameters maintained in PTA welding process.

\begin{tabular}{lcc}
\hline Sl. number & Technology & Parameter \\
\hline$(1)$ & Welding process & PTA \\
$(2)$ & Current & $150 \mathrm{~A}$ \\
$(3)$ & Polarity & $\mathrm{DC}$ \\
$(4)$ & Voltage & $22 \mathrm{~V}$ \\
$(5)$ & Powder feed rate & $30 \mathrm{~g} / \mathrm{min}$ \\
$(6)$ & Shielding gas & Argon \\
$(7)$ & Shielding gas flow & $12 \mathrm{~L} / \mathrm{min}$ \\
$(8)$ & rate & $3 \mathrm{~mm} / \mathrm{s}$ \\
$(9)$ & Travel speed & Vermiculate powder \\
\hline
\end{tabular}

weldment at the operating temperatures should be high to avoid debonding. Therefore, the weldment should be able to withstand the tensile force at higher operating temperatures for which hot tensile tests have been carried out at those temperatures for both the parent metal and the weldment separately as per ASTM E8 and then compared. However, the compressive stress acting on the hardfaced deposit is around $15 \mathrm{MPa}$ only, which is very much less than the yield stress of the deposit. Hence, the hardfaced deposit is very safe due to compressive stress [10].

\section{Experimental Setup}

Table 1 shows the process parameters for hardfacing by PTAW for lower dilution and finer microstructure so that maximum hardness of the coating can be achieved [11]. The presence of silicon creates fluidic property. Colmonoy has $4 \%$ of silicon and hence it acquires fluidic property while being hardfaced and hence it is better to coat it inside the groove $[12,13]$. The 
TABLE 2: Chemical composition of $316 \mathrm{~L}(\mathrm{~N})$ SS and Colmonoy 5.

\begin{tabular}{|c|c|c|c|c|c|c|c|c|c|c|c|}
\hline Material & $\mathrm{C}$ & $\mathrm{Mn}$ & $\mathrm{Si}$ & $\mathrm{P}$ & S & $\mathrm{Cr}$ & Mo & $\mathrm{Ni}$ & $\mathrm{N}$ & $\mathrm{Fe}$ & $\mathrm{B}$ \\
\hline $\begin{array}{l}316 \mathrm{~L}(\mathrm{~N}) \\
\text { SS }\end{array}$ & 0.03 & 2.0 & 0.75 & 0.045 & 0.03 & 18 & 3.0 & 14 & 0.14 & $\begin{array}{c}62.05 \\
(\text { As Bal) }\end{array}$ & - \\
\hline $\begin{array}{l}\text { Colmonoy } \\
5 \text { powder }\end{array}$ & 0.6 & 0.1 & 3.8 & - & - & 11.5 & - & $\begin{array}{c}77 \text { (As } \\
\text { Bal) }\end{array}$ & - & 4.4 & 2.6 \\
\hline
\end{tabular}

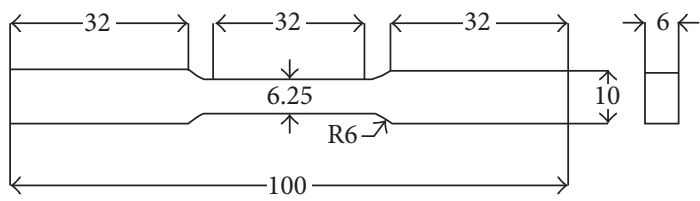

(a)



(b)

FIGURE 2: Geometry of (a) patent metal specimens (as per ASTM E8) and (b) weldment specimens (as per ASTM E8 with the weld metal at the centre as per ASME section IX).

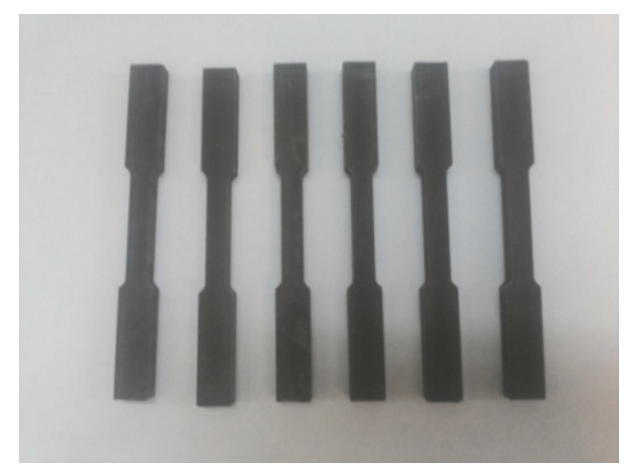

(a)

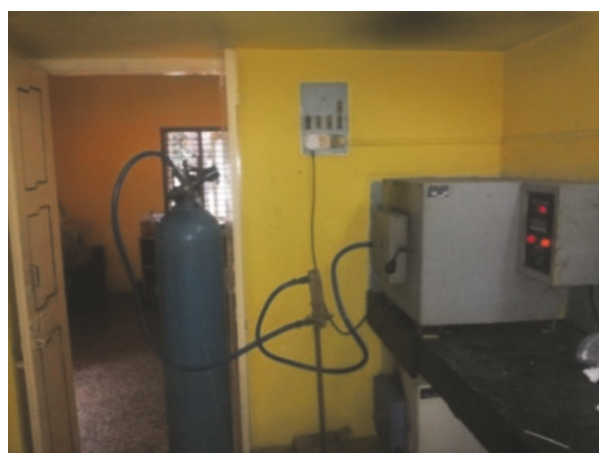

(c)

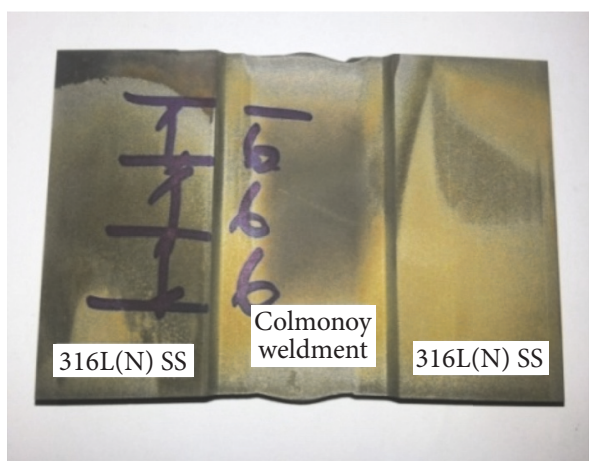

(b)

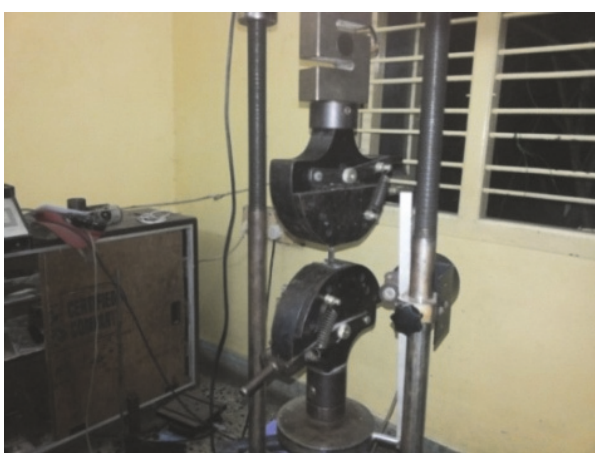

(d)

Figure 3: (a) Some of the samples of parent metal. (b) Welded plate for tensile test specimens. (c) Stress relieving procedure. (d) Tensile test setup for room temperature tests.

chemical compositions of the base metal (316 LN SS) and the hardfacing alloy (Colmonoy 5) are given in Table 2 [14-16].

The geometry of the tensile specimen as per the ASTM E8 standard is shown in Figure 2 [17]. The tensile specimens of the parent metal are shown in Figure 3(a). Figure 3(b) shows the $316 \mathrm{~L}(\mathrm{~N})$ SS plate welded with Colmonoy 5 at the centre as per the geometry recommended by the ASME section IX [18]. This plate was cut into weld specimens as per the geometry of the ASTM E8. Stress relieving operation was carried out for the welded specimens at $400^{\circ} \mathrm{C}$ in a Muffle furnace with argon purging at the rate of $0.5 \mathrm{lit} / \mathrm{min}$ for 2 hours to remove the process-induced residual stresses before tensile testing as shown in Figure 3(c). Six specimens were tested at each temperature and the mean of the values has been taken as the tensile properties at that temperature. Yield stress is calculated for the tensile specimens by $0.5 \%$ offset 


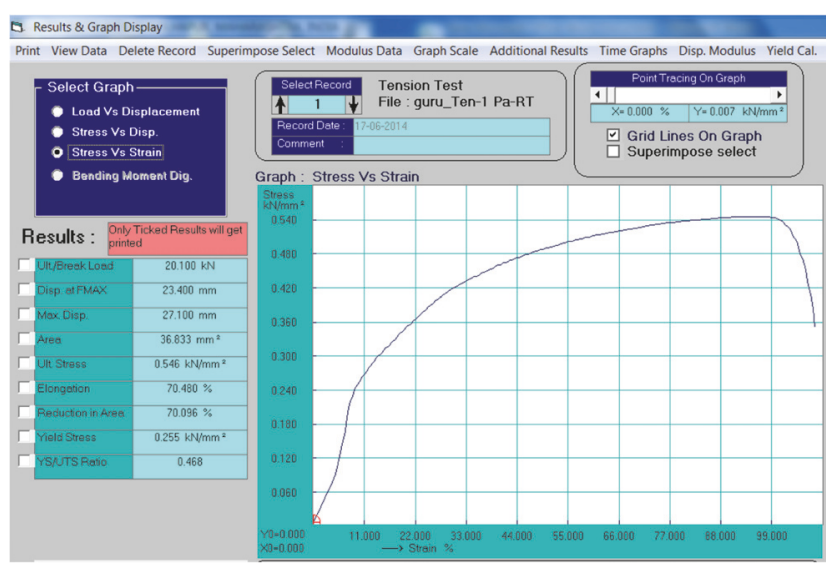

(a)

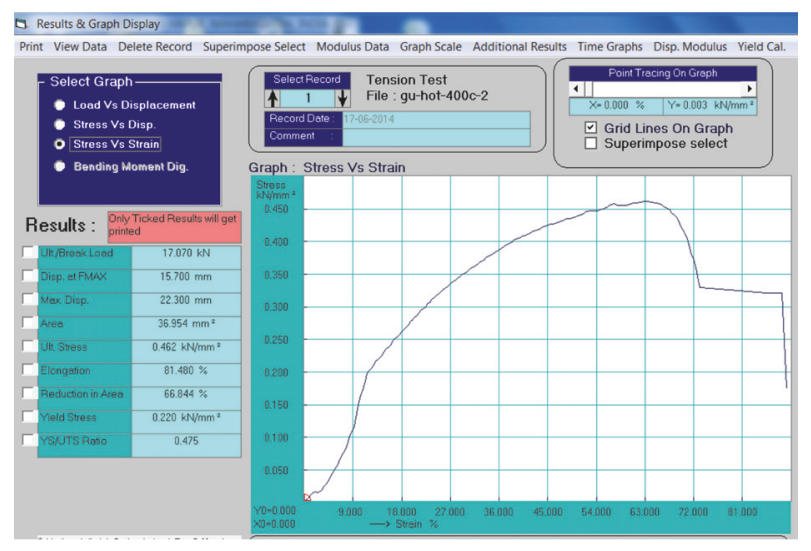

(c)

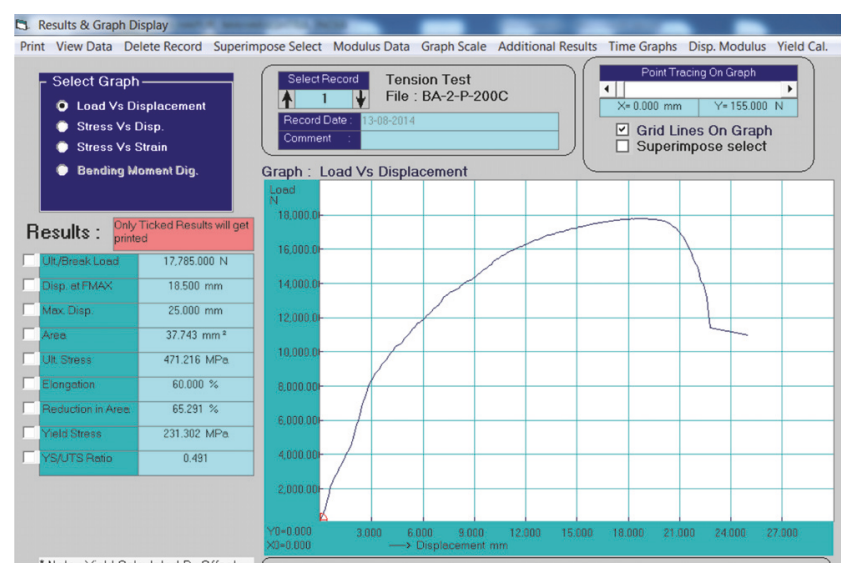

(b)
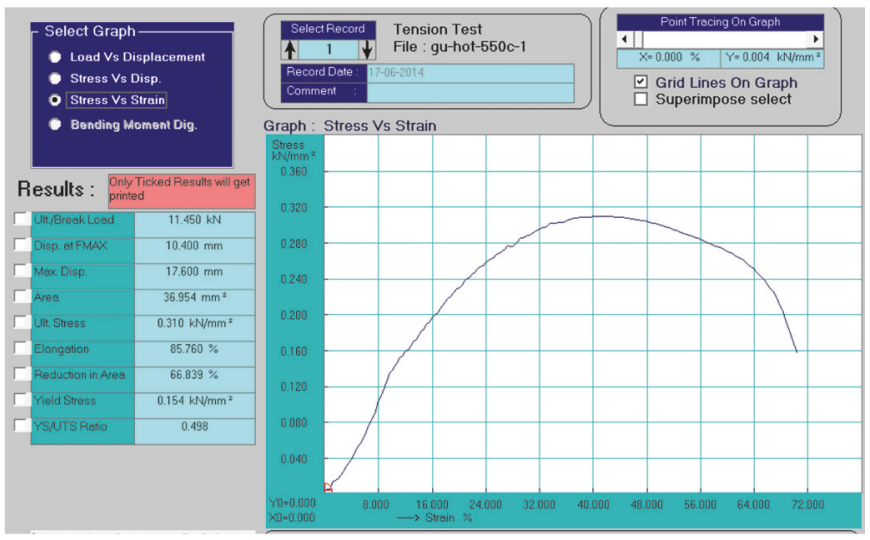

(d)

FIGURE 4: Stress-strain graphs of the parent metal at (a) room temperature, (b) $200^{\circ} \mathrm{C}$, (c) $400^{\circ} \mathrm{C}$, and (d) $550^{\circ} \mathrm{C}$.

method as per the ASTM E8. Tensile testing facility for room temperature test is shown in Figure 3(d). Hot tensile tests are carried out using a tubular furnace in which the hot zone is achieved by heating coils. The tubular furnace which is shown in Figure 5(b) is provided with K-type thermocouple to measure and a controller to control the desired temperature of the tests. The tensile specimen is held by heat resistance holders and insulators. Hot tensile tests were carried out as per ASTM E21 [19].

\section{Results and Discussion}

The results of the hot tensile tests are discussed for the parent metal separately and the weldment separately and then the corresponding properties of the parent metal and the weldment are compared for the compatibility.

5.1. Effects of Operating Temperatures on the Tensile Properties of the Parent Metal. The hot tensile results of the parent metal at different operating temperatures are given in Figures 4(a) $-4(\mathrm{~d})$.

From Figure 5(c), it is seen that as the operating temperature increases, the ductility of the parent metal increases. Increase in stress beyond the yield point gives rise to reduction in cross-sectional area of the specimens. This leads to necking of the specimens. The necking region of the specimen is small at room temperature and it increases as the temperature increases. This is due to the fact that the ductility of the parent metal increases as the temperature increases. From the mean value of six specimens tested at each temperature, the tensile properties are discussed. Figure 6(a) shows the variation in UTS and YS for different operating temperatures.

Figure 6(a) shows the changes in UTS of the parent metal at different operating temperatures. At the room temperature, the UTS is found to be $529 \mathrm{MPa}$. At the shutdown temperature of $200^{\circ} \mathrm{C}$, it decreases to $474.5 \mathrm{MPa}$. For a rise of $170^{\circ} \mathrm{C}$ temperature, the UTS decreases by $10.3 \%$. At the normal operating temperature of $400^{\circ} \mathrm{C}$, it decreases to $446.2 \mathrm{MPa}$, amounting to a reduction of just $6 \%$ compared to shutdown temperature. But, at the peak operating temperature of $550^{\circ} \mathrm{C}$, UTS decreases to $373.7 \mathrm{MPa}$, amounting to a reduction of $16.2 \%$ compared to normal operating temperature. In general, though the UTS of the parent metal decreases as the operating temperature increases, the reduction gradient of the UTS is marginal till the normal operating temperature and it is maximum between normal operating temperature $\left(400^{\circ} \mathrm{C}\right)$ and peak operating temperature $\left(550^{\circ} \mathrm{C}\right)$. This could be due 


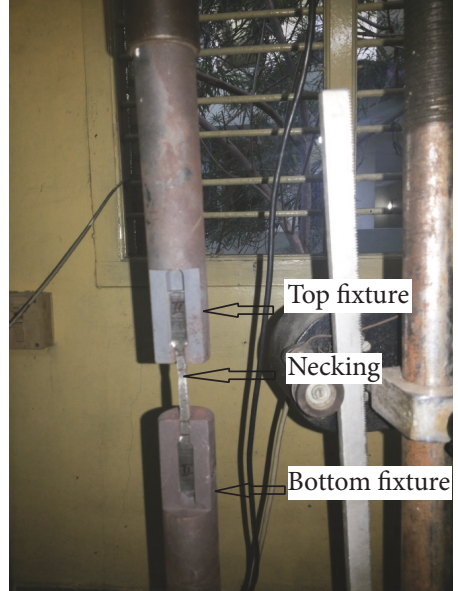

(a)

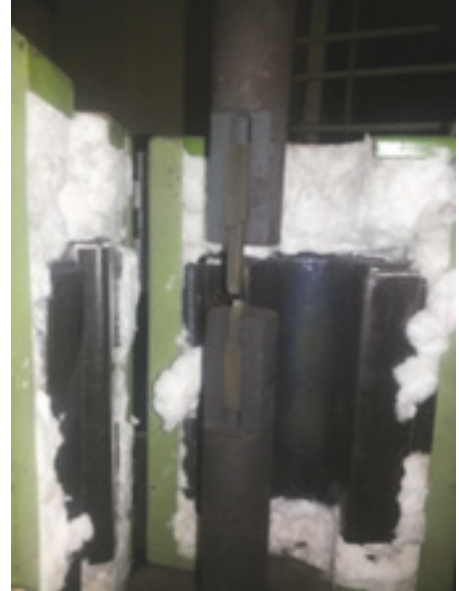

(b)

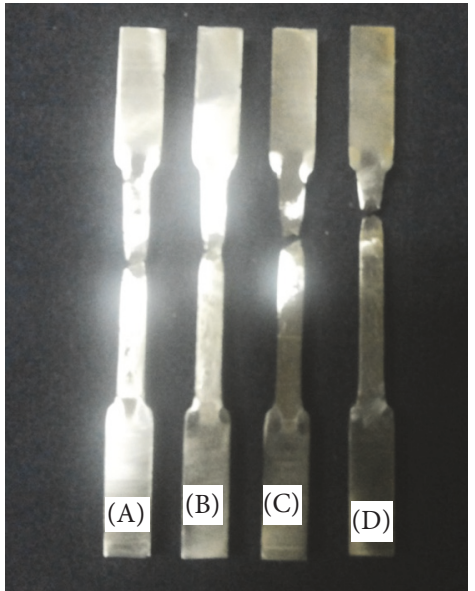

(c)

Figure 5: (a) Parent metal showing necking at room temperature. (b) Parent metal at the end of $400^{\circ} \mathrm{C}$ test. (c) Tested specimens of the parent metal: (A) room temperature, (B) $200^{\circ} \mathrm{C}$, (C) $400^{\circ} \mathrm{C}$, and (D) $550^{\circ} \mathrm{C}$.

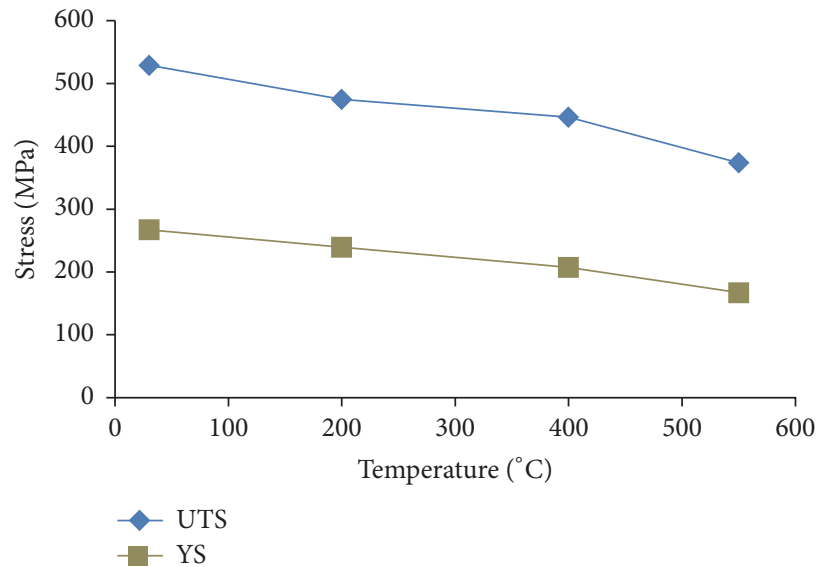

(a)

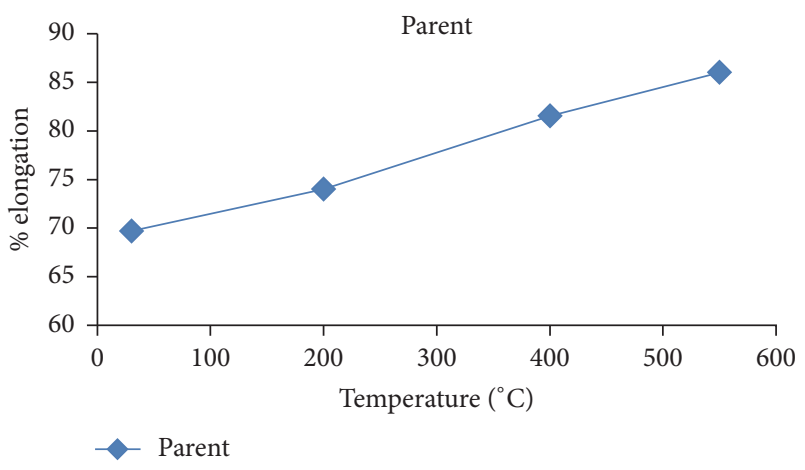

(b)

FIGURE 6: Behaviour of the parent metal at different operating temperature. (a) UTS and YS. (b) \% elongation.

to the precipitation of alloy carbide at the grain boundaries of austenite because the formation of carbide precipitation starts at $425^{\circ} \mathrm{C}$ (ASME volume 9) for austenitic stainless steel. As the temperature increases, the strain corresponding to UTS decreases from $90 \%$ at room temperature to $40 \%$ at the peak operating temperature.

The trend of decrease in yield stress with increase in operating temperatures is almost similar to that of UTS. Though the YS of the parent metal decreases as the operating temperature increases, the reduction gradient of the YS is maximum between normal operating temperature $\left(400^{\circ} \mathrm{C}\right)$ and peak operating temperature $\left(550^{\circ} \mathrm{C}\right)$ similar to that of UTS. From Figure 6(b), it is seen that the \% elongation is found to be maximum between the normal operating temperature and the peak temperature. The trend of $\%$ elongation with the temperature shows the ideal behaviour and the homogeneity of the austenitic $316 \mathrm{~L}(\mathrm{~N})$ SS as it is a good conductor of heat with thermal conductivity of $17 \mathrm{~W} / \mathrm{m} . \mathrm{K}$.
As the temperature increases, the ductility of the parent metal increases which eventually increases the $\%$ elongation.

\subsection{Effects of Operating Temperatures on the Tensile Properties} of the Weldment. For assessing bonding nature between the base metal and deposit, the tensile properties of the weldment were studied at three different operating temperatures. The hot tensile results of the weldment at different operating temperatures are given in Figures 7(a)-7(d).

From Figure 7(a), it is seen that the weldment has undergone brittle fracture at room temperature. Due to this fact, the yield stress property is not applicable at this temperature. From the mean value of six specimens tested at each temperature, the tensile properties are discussed. Figure 9 shows the changes in UTS of the weldment at different operating temperatures. From Figure 8(b), it is seen that the specimens break at the parent metal only but not at the weld metal region at all the operating temperatures. It shows that the weldment 


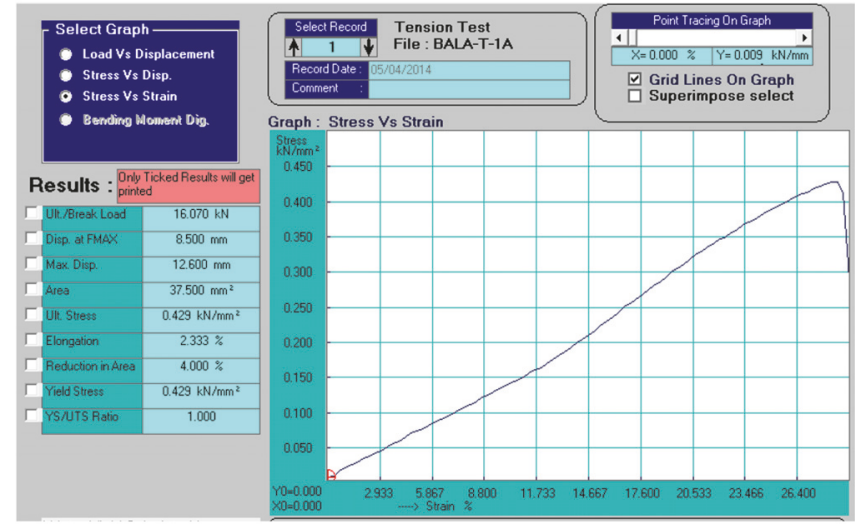

(a)

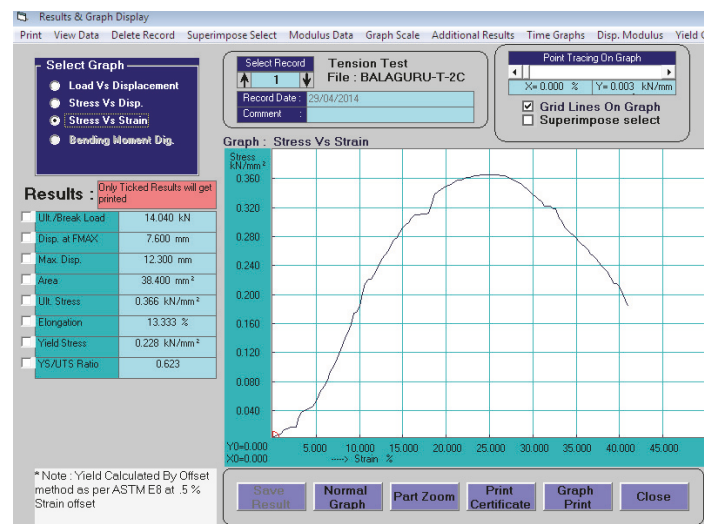

(c)



(b)



(d)

Figure 7: Stress-strain graphs of the weldment at (a) room temperature, (b) $200^{\circ} \mathrm{C}$, (c) $400^{\circ} \mathrm{C}$, and (d) $550^{\circ} \mathrm{C}$.



(a)



(b)

Figure 8: (a) Weldment at the end of $200^{\circ} \mathrm{C}$ test. (b) Tested specimens of the weldment at (A) room temperature, (B) $200^{\circ} \mathrm{C}$, (C) $400^{\circ} \mathrm{C}$, and (D) $550^{\circ} \mathrm{C}$.

is stronger than the parent metal and it is strong enough to take tensile load. The failure takes place at the parent metal which is more ductile and eventually fails by neck formation.
At the room temperature, the UTS is found to be $433.5 \mathrm{MPa}$. At the shutdown temperature of $200^{\circ} \mathrm{C}$, it decreases to $375.8 \mathrm{MPa}$. For a rise of $170^{\circ} \mathrm{C}$ temperature, the 


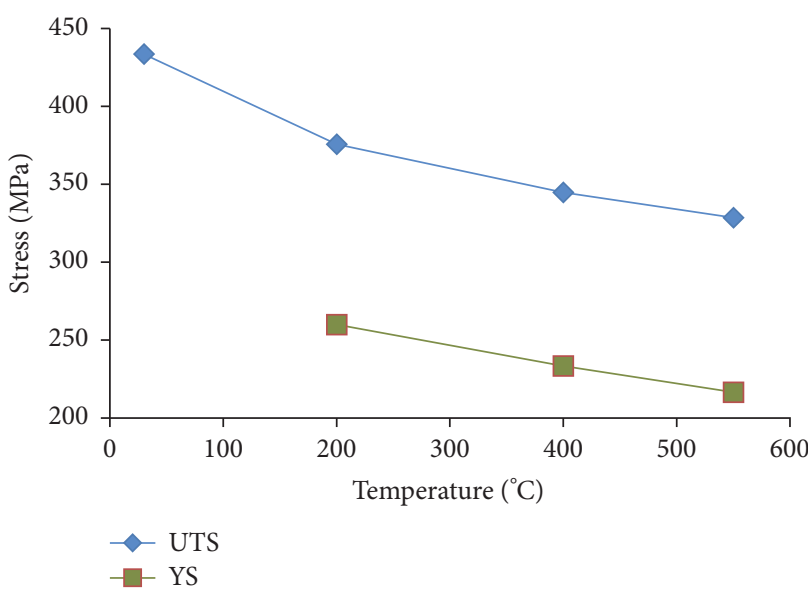

(a)

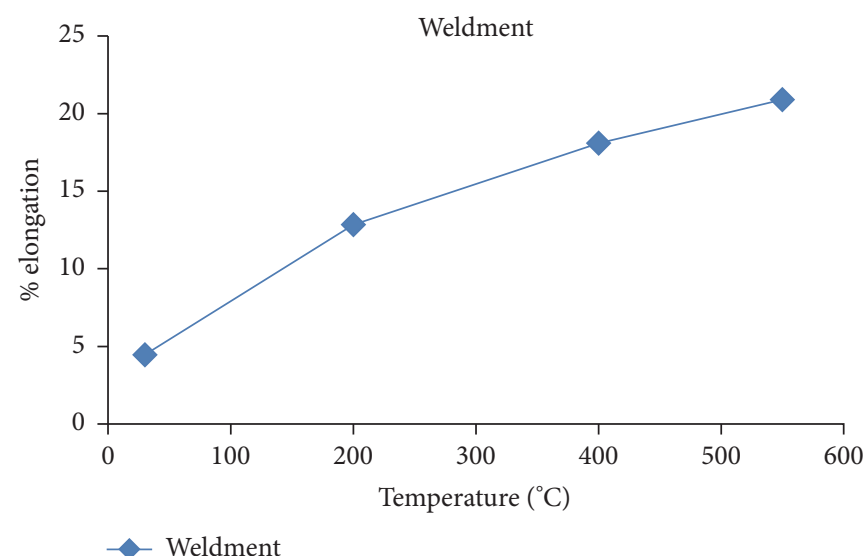

(b)

FIGURE 9: Behaviour of the weldment at different operating temperature. (a) UTS and YS. (b) \% elongation.



(a)

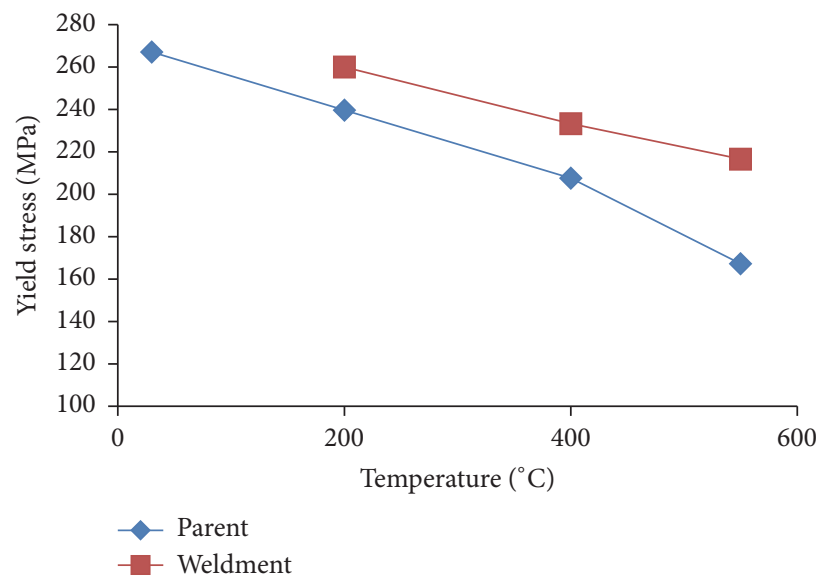

(b)

FIGURE 10: Parent metal and weld metal at different operating temperatures showing (a) UTS and (b) YS.

UTS decreases by $13.3 \%$. At the normal operating temperature of $400^{\circ} \mathrm{C}$, it decreases to $344.8 \mathrm{MPa}$, amounting to a reduction of just $8.25 \%$ compared to shutdown temperature. But, at the peak operating temperature of $550^{\circ} \mathrm{C}$, the UTS decreases to $328.6 \mathrm{MPa}$, amounting to a reduction of only $4.7 \%$ compared to normal operating temperature. In general, though the UTS of the weldment decreases as the operating temperature increases, the reduction gradient of the UTS is maximum between the room temperature and the shutdown temperature $\left(200^{\circ} \mathrm{C}\right)$. Within the operating temperatures, the reduction gradient of the UTS is minimal. As the temperature increases, the strain corresponding to UTS decreases from around $27 \%$ at room temperature to around $18 \%$ at the peak operating temperature. From Figure 9(a), it is seen that though the yield stress decreases with the increase in temperature, the reduction gradient is found to be maximum between $200^{\circ} \mathrm{C}$ and $400^{\circ} \mathrm{C}$. The $\%$ elongation of the weldment decreases from $8.38 \%$ between $\mathrm{RT}$ and $200^{\circ} \mathrm{C}$ to $2.8 \%$ between $400^{\circ} \mathrm{C}$ and $550^{\circ} \mathrm{C}$. Therefore, the weldment has the ability to maintain its hardness even at $550^{\circ} \mathrm{C}$. Tested specimen of the weldment at the end of $200^{\circ} \mathrm{C}$ test is shown in Figure 8(a).
5.3. Comparison of Tensile Properties of the Parent Metal and the Weldment at Different Operating Temperatures. Figure 10(a) shows the variation in UTS of both the parent metal and weldment at different operating temperatures. This comparison will help to confirm the suitability of the Colmonoy which is to be hardfaced on the austenitic stainless steel.

From Figure 10(a), it is evident that UTS of both the parent metal and the weldment decreases with increase in operating temperatures. Though the deposit is brittle in nature, its UTS at any tested temperature lies between $80 \%$ and $90 \%$ of that of the parent metal. Hence the Colmonoy is suitable to be hardfaced on the austenitic stainless steel. From Figure 10(b), it is seen that YS of both the parent metal and the weldment decreases with increase in operating temperatures. At all the operating temperatures, the YS of the weldment is higher than that of the parent metal. At peak temperature, the weldment possesses $130 \%$ of YS of the parent metal. Therefore, the weldment is rigid and is capable of carrying higher compressive loads. Figures 11(a) and 11(b) show the SEM micrographs captured at the fractured portion of the 




(a)



(b)

FIGURE 11: SEM micrographs at the fractured portion of (a) parent metal and (b) weldment.

parent metal and the weldment tested at room temperature, respectively.

The dull and fibrous portion of the fractured surface seen in Figure 11(a) indicates that the parent metal has undergone ductile fracture. The bright and crystalline nature of the fractured portion seen in Figure 11(b) indicates that the weldment has undergone brittle fracture. The SEM micrographs reveal finer grains at higher temperatures for both the parent metal and the weldment.

\section{Conclusions}

From the hot tensile tests carried out on the parent metal and the weldment, we arrive at the following conclusions:

(i) At the normal operating temperature of $400^{\circ} \mathrm{C}$, the parent metal possesses $85 \%$ of its UTS of that of room temperature. Even at the peak operating temperature of $550^{\circ} \mathrm{C}$, the parent metal possesses $71 \%$ of its UTS of that of room temperature. Therefore, the UTS of the base metal has not been significantly affected at different operating temperatures.

(ii) At the normal operating temperature of $400^{\circ} \mathrm{C}$, the parent metal possesses $78 \%$ of its YS of that of room temperature. Even at the peak operating temperature of $550^{\circ} \mathrm{C}$, the parent metal possesses $63 \%$ of its YS of that of room temperature. Therefore, the YS of the parent metal has not been significantly affected at different operating temperatures.

(iii) At the normal operating temperature of $400^{\circ} \mathrm{C}$, the weldment possesses $80 \%$ of its UTS of that of room temperature. Even at the peak operating temperature of $550^{\circ} \mathrm{C}$, the weldment possesses $76 \%$ of its UTS of that of room temperature. Therefore, the UTS of the weldment has not been significantly affected at different operating temperatures.

(iv) The reduction gradient of the yield stress of the weldment is found to be maximum between shutdown temperature $\left(200^{\circ} \mathrm{C}\right)$ and normal operating temperature $\left(400^{\circ} \mathrm{C}\right)$. However, the yield stress of the weldment is higher than that of the parent metal at all the operating temperatures. Even at peak temperature $\left(550^{\circ} \mathrm{C}\right)$, the weldment possesses more than $130 \%$ of yield stress compared to that of parent metal. This confirms that the hardfacing alloy maintains its properties at all the operating temperatures.

(v) Since the weldment specimens break at the parent metal region at all the operating temperatures after the formation of neck, the interface is strong enough to take the tensile load even though the difference in coefficients of thermal expansion exists between the substrate and the deposit. Though the deposit is brittle in nature, its UTS at any tested temperature lies between $80 \%$ and $90 \%$ of that of the parent metal. Hence the Colmonoy possesses good tensile properties at higher temperatures and hence it is suitable to be hardfaced on the austenitic stainless steel for better bonding at the interface.

\section{Conflicts of Interest}

The authors declare that they have no conflicts of interest.

\section{Acknowledgments}

The authors are thankful to Dr. S. Ramesh, Head, Department of Mechanical Engineering, KCG College of Technology, for his valuable suggestions.

\section{References}

[1] B. V. Cockeram, R. F. Buck, and W. L. Wilson, "Laboratory galling tests of several commercial cobalt-free weld hardfacing alloys," Surface \& Coatings Technology, vol. 94-95, pp. 495-500, 1997.

[2] B. V. Cockeram, "The fracture toughness and toughening mechanisms of nickel-base wear materials," Metallurgical and Materials Transactions A, vol. 33, pp. 33-56, 2002.

[3] F. Jiang, K. Zhao, and J. Sun, "Evaluation o interfacial crack growth in biomaterial metallic joints loaded by symmetric three-point bending," International Journal of Pressure Vessels and Piping, vol. 80, pp. 129-137, 2003.

[4] A. K. Bhaduri, R. Indira, S. K. Albert, B. P. S. Rao, S. C. Jain, and S. Asokkumar, "Selection of hardfacing material for 
components of the Indian prototype fast breeder," Journal of Nuclear Materials, vol. 334, pp. 109-114, 2004.

[5] Z. Ming-Liang and X. Fu-Zhen, "Effect of temperature on tensile and impact behavior of dissimilar welds of rotor steels," Materials and Design, vol. 31, pp. 3346-3352, 2010.

[6] N. Elango, A. A. M. Faudzi, A. Hassan, and M. R. M. Rusydi, "Experimental investigations of skin-like material and computation of its material properties," International Journal of Precision Engineering and Manufacturing, vol. 15, no. 9, pp. 1909-1914, 2014.

[7] S. Balaguru, K. Shashi, M. Vela, and P. Chellapandi, “Thermo mechanical analysis of ss304 circular grid plate hardfaced with colmonoy," Applied Mechanics and Materials, vol. 229-231, pp. 710-717, 2012.

[8] S. Balaguru, R. Saran, K. Vela Murali, and P. Chellapandi, "Variation in residual stresses due to thermal cycling induced on the hardfaced grid plate in PFBR," Applied Mechanics and Materials, vol. 591, pp. 98-102, 2014.

[9] S. Balaguru, V. Murali, and P. Chellapandi, "Measurement of the residual stresses and investigation of their effects on a hardfaced gridplate due to thermal cycling in a pool type sodium-cooled fast reactor," Science and Technology of Nuclear Installations, vol. 2016, Article ID 8353256, 8 pages, 2016.

[10] P. Chellapandi, P. Puthiyavinayagam, V. Balasubramaniyam et al., "Development of innovative reactor assembly components towards commercialization of future FBRs," Energy Procedia, vol. 7, pp. 359-366, 2011.

[11] S. Balaguru, K. Deenadayalan, V. Murali, and P. Chellapandi, "Influence of welding speed over dilution for circular grid plate hardfaced with colmonoy-5," Applied Mechanics and Materials, vol. 565, pp. 53-58, 2014.

[12] K. Halil Ibrahim and S. Ramazan, "Study of microstructure, tensile and hardness 304 stainless steel joined by TIG welding," International Journal of Science and Technology, vol. 2, pp. 163168, 2013.

[13] I. A. Palani, N. J. Vasa, M. Singaperumal, and T. Okada, "Investigation on laser-annealing and subsequent laser-nanotexturing of amorphous silicon (a-Si) films for photovoltaic application," Journal of Laser Micro Nanoengineering, vol. 5, no. 2, pp. 150155, 2010.

[14] D. Kesavan and M. Kamaraj, "The microstructure and high temperature wear performance of a nickel base hardfaced coating," Wear, vol. 204, pp. 4034-4043, 2010.

[15] R. Prabu and S. Ramesh, "Structure and hardness of tic coating by laser cladding," International Journal of Applied Engineering Research, vol. 10, pp. 299-305, 2015.

[16] P. Suresh, R. Venkatesan, T. Sekar, N. Elango, and V. Sathiyamoorthy, "Optimization of intervening variables in MicroEDM of SS 316L using a genetic algorithm and response-surface methodology," Strojniski Vestnik/Journal of Mechanical Engineering, vol. 60, no. 10, pp. 656-664, 2014.

[17] ASTM E8, Standard Test Method for Tension Testing of Metallic Materials, ASTM International.

[18] ASM Handbook, Section IX, ASM International, 2004.

[19] ASTM standard E21, Tensile testing of metals at elevated temperatures, ASTM International. 


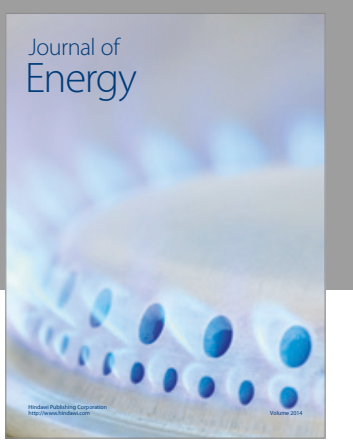

Journal of

Industrial Engineering
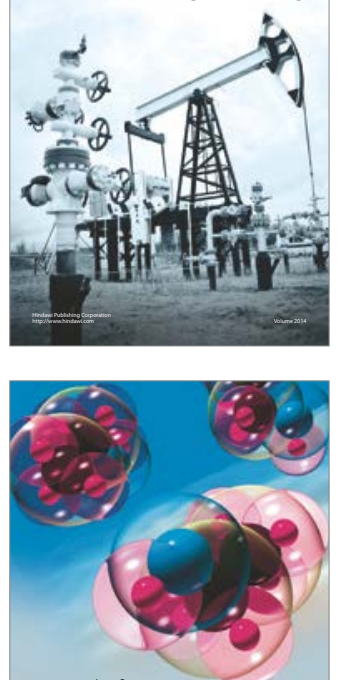

Fuels



The Scientific World Journal
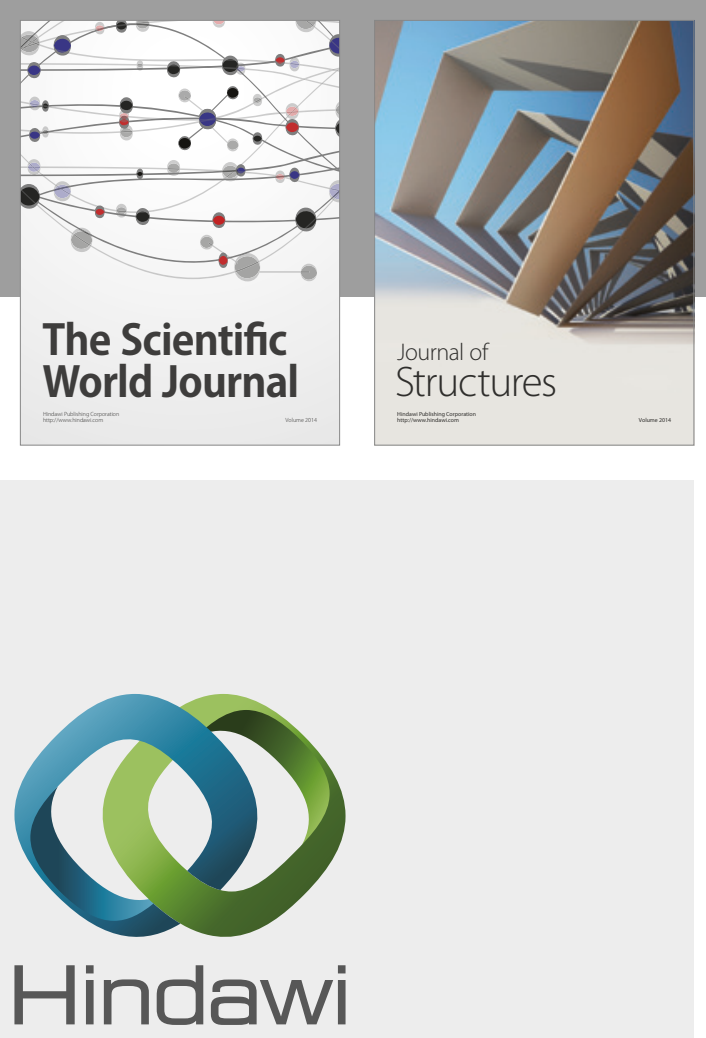

Submit your manuscripts at

https://www.hindawi.com


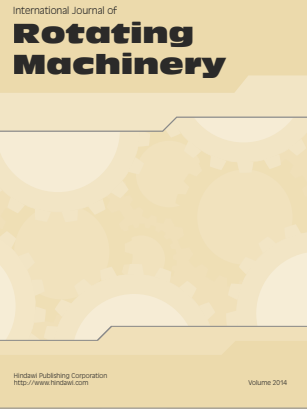

Journal of

Petroleum Engineering

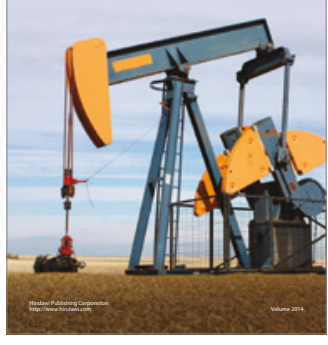

Journal of
Solar Energy
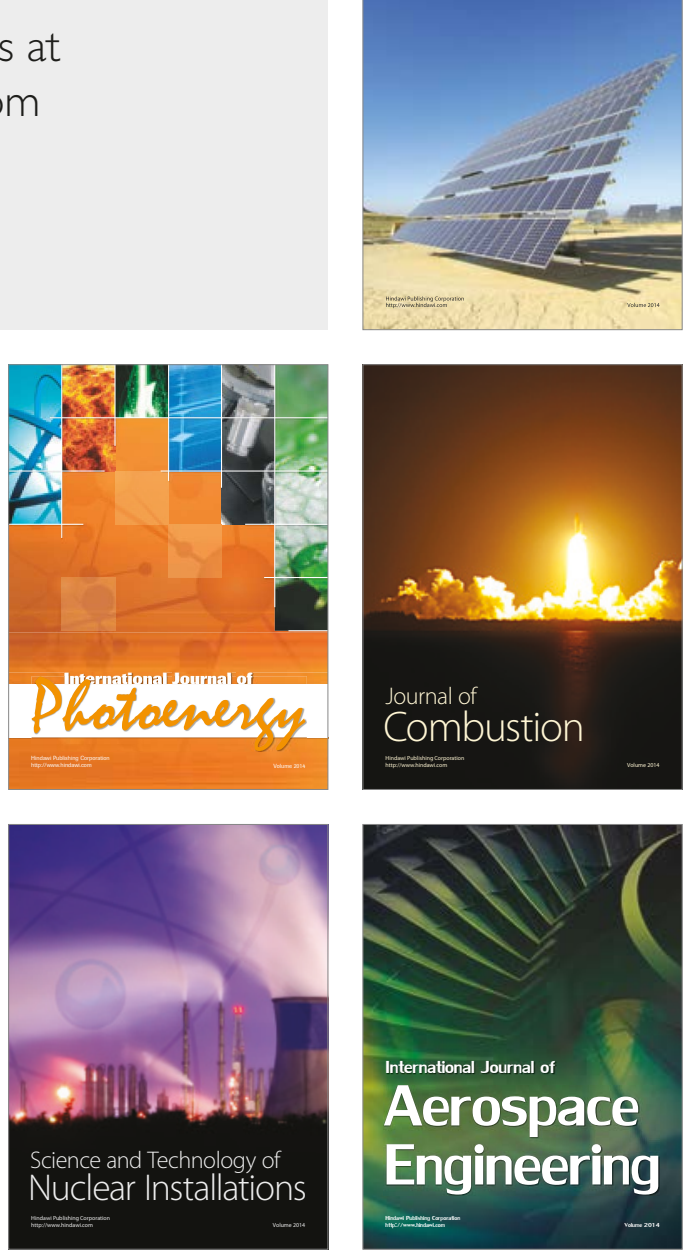